ORIGINAL ARTICLE

\title{
Molecular strain identification of the Mycobacterium tuberculosis complex in archival tissue samples
}

\author{
A R Zink, A G Nerlich
}

J Clin Pathol 2004;57:1 185-1192. doi: 10.1136/icp.2003.015719

See end of article for authors' affiliations

....................

Correspondence to: $\operatorname{Dr} A$ G Nerlich, Institute of Pathology, Academic Teaching Hospital München-Bogenhausen, D-81925 München, Germany; Andreas. Nerlich@extern. Irz-muenchen.de

Accepted for publication 3 February 2004

\begin{abstract}
Aims: To investigate the use of different molecular analyses that can identify distinct strains of human pathogenic mycobacteria in formalin fixed and paraffin wax embedded archival tissue samples to see whether it is possible to differentiate between the members of the Mycobacterium tuberculosis complex ( $M$ tuberculosis, $M$ bovis, $M$ africanum, $M$ microti, or $M$ canettii) and/or substrains in a high number of samples. This would be of interest for identifying individual infection traits and superinfection by different mycobacterial strains.

Methods: Forty nine archival tissue samples with clinically and/or histologically suspected tuberculosis infection were subjected to molecular DNA analysis.

Results: The molecular analysis revealed the presence of $M$ tuberculosis complex DNA in 20 samples, whereas acid fast bacilli could be detected by Ziehl-Neelsen staining in only eight samples. All IS6110 positive samples were further characterised by spoligotyping and seven cases provided $M$ tuberculosis specific signatures, whereas $M$ bovis specific signatures were obtained in four cases. The analysis of mtp40, oxyR, and pncA partial gene sequences confirmed the presence of $M$ tuberculosis in six cases and $M$ bovis in one case. The amplification and sequencing of four further genetic regions (katG, gyrA, TbDl, RD9) characterised six "modern" $M$ tuberculosis strains belonging to genetic groups 2 or 3 .

Conclusion: This study provides clear evidence that archival paraffin wax embedded material can be used for further studies on the strain identification of $M$ tuberculosis complex strains and can therefore unequivocally be used for the study of the epidemiology and evolution of tuberculosis pathogens.
\end{abstract}

n general, the sensitivity of routinely applied histochemical staining for acid fast bacilli in paraffin wax embedded tissues is low and allows the detection of human pathogenic members of the Mycobacterium tuberculosis complex in only a proportion of affected cases. Frequently, even when lesions appear morphologically to be typical for an active tuberculosis (TB) infection only a few cases are stained positive. Therefore, polymerase chain reaction (PCR) based amplification of mycobacterial DNA in paraffin wax embedded material is increasingly used to confirm suspected mycobacterial infections. Several previous studies provide data on this issue and suggest that this approach has considerably higher sensitivity. ${ }^{1-5}$

Despite this diagnostically important improvement, there have been few reports on molecular techniques for the identification of different mycobacterial strains in archival tissue material. This is becoming increasingly important as the tracing of re-emerging disease, the identification of de novo or superinfection, and/or the identification of "new" substrains with higher resistance against multidrug treatment potentially become clinically relevant. ${ }^{6}$

\section{"There have been few reports on molecular techniques for the identification of different mycobacterial strains in archival tissue material"}

To the best of our knowledge, until now only two studies have used emerging molecular techniques such as spoligotyping on paraffin wax embedded tissue samples to identify $M$ tuberculosis complex strains. ${ }^{78}$ These studies showed that formalin fixed and paraffin wax embedded tissue samples from patients with positive TB culture and/or clinically unambiguously identified tuberculosis can be used for the detection and strain differentiation of members of the
$M$ tuberculosis complex. However, no data are as yet available on the rate of success of those techniques in archival material or on the rate of positive strain identification in unclear or clinically suspected, but uncertain, cases.

Our present study applied the spoligotyping technique and a panel of distinct primer pairs to identify (sub)strains of the $M$ tuberculosis complex. We describe here the technical details, and provide clear evidence that these approaches can successfully be applied to archival paraffin wax embedded tissue samples in approximately two thirds of cases with molecularly confirmed $M$ tuberculosis complex infection.

\section{MATERIAL AND METHODS}

Samples and study population

Our study was conducted on routinely formalin fixed and paraffin wax embedded biopsy tissue samples from 48 patients where the presence of tuberculosis had been suspected either by clinical assessment and/or histomorphological investigation. All samples were consecutively selected from the files of the institute of pathology of the Academic Hospital Munich-Bogenhausen, Germany between June 2001 and June 2003. Cases without histomorphological evidence for granulomatous or necrotising inflammation were excluded from our study, even when the clinical differential diagnosis had included TB. Table l presents detailed information on all cases, including clinical diagnosis, localisation of the biopsy, and major histopathological features. Furthermore, we listed the nationality of the affected individuals so that we could potentially trace back the TB strains on a geographical basis. Accordingly, all samples except two (46) showed typical epitheloid granulomas. In 27 cases, giant cells of the Langhans type were

Abbreviations: $P C R$, polymerase chain reaction; PZA, pyrazinamide; $\mathrm{RD9}$, region of difference 9; TB, tuberculosis 
present and 32 cases revealed necrosis, which showed in most instances the typical features of caseous necrosis. Therefore, in each of the 48 cases either epitheloid granulomas or necrosis was present. Using Ziehl-Neelsen staining, only eight samples contained typical acid fast bacilli, and this histochemical staining method provided no diagnostic information in the remaining samples (table 1).

\section{Sample preparation and molecular identification of M tuberculosis complex DNA}

As a first step, the presence of $M$ tuberculosis complex DNA was analysed in all 48 samples. Two to five $5 \mu \mathrm{m}$ thick sections were prepared from each appropriate paraffin wax block and placed into a sterile tube. All procedures were performed under strictly controlled precautions-such as the use of new cutting blades for each case-to avoid crosscontamination between the samples. Subsequently, the samples were dewaxed in xylene and the DNA was extracted using the QIAamp DNA mini kit (Qiagen, Hilden, Germany), according to standard protocols.
All samples were tested for the presence of $M$ tuberculosis complex DNA by the amplification of a $123 \mathrm{bp}$ fragment of the insertion sequence IS6110 (table 2)..$^{9}{ }^{10}$ In parallel, a $202 \mathrm{bp}$ fragment of the human $\beta$ actin gene was amplified to test for the presence of amplifiable DNA and to assure that the PCR reaction was not inhibited.

\section{Confirmation of amplification specificity}

The specificity of the $123 \mathrm{bp}$ PCR product of IS6110 was confirmed either by restriction enzyme digestion or direct sequencing. For the digestion, $8 \mu \mathrm{l}$ of the PCR product was incubated with 10 U Hae III (Roche Diagnostics, Mannheim, Germany) for two hours at $37^{\circ} \mathrm{C}$. This resulted in a $94 \mathrm{bp}$ and a $29 \mathrm{bp}$ fragment. In several cases, the nucleotide sequences of the PCR products were determined. After electrophoresis on a $4 \%$ low melting point agarose gel, the respective fragment of the PCR reaction was eluted with a purification kit (Freeze'n Squeeze; Bio-Rad, Hercules, California, USA). Using the eluted DNA, cycle sequencing was performed with the big dye terminator cycle sequencing kit (Applied

Table 1 Summary of the clinical and histomorphological data from our study population

\begin{tabular}{|c|c|c|c|c|c|c|c|c|c|}
\hline Case & Age & Sex & $\begin{array}{l}\text { Country (of } \\
\text { origin) }\end{array}$ & Clinical diagnosis & Localisation & $\begin{array}{l}\text { Epitheloid } \\
\text { granuloma }\end{array}$ & Giant cells (LH) & Necrosis & ZN staining \\
\hline 1 & 61 & $\mathrm{~F}$ & Germany & $\mathrm{TB}$ & Distal tibia & + & + & + & - \\
\hline 2 & 50 & $\mathrm{~F}$ & Germany & Uro TB & Kidney & + & + & + & - \\
\hline 3 & 64 & $\mathrm{~F}$ & Germany & Tumour & Liver & + & + & - & - \\
\hline 4 & 79 & $\mathrm{~F}$ & Germany & Abscess & Vulva & + & - & + & - \\
\hline 5 & 67 & $\mathrm{~F}$ & Germany & TB & Paravertebra & + & - & - & - \\
\hline 6 & 42 & $M$ & Arabia & Lymphoma & Lymph node & + & + & + & - \\
\hline 7 & 74 & $M$ & Poland & Inflammation & Epididymis & + & + & + & - \\
\hline 8 & 79 & $M$ & Germany & Tumour & Prostate & + & - & - & - \\
\hline 9 & 40 & $\mathrm{~F}$ & Germany & $\mathrm{TB}$ & Lymph node & + & + & + & + \\
\hline 10 & 65 & $M$ & Germany & Spondylitis & Vertebra & + & - & + & - \\
\hline 11 & 23 & $M$ & Vietnam & Lymphoma & Lymph node & + & + & + & - \\
\hline 12 & 70 & $\mathrm{~F}$ & Germany & Granuloma & Finger & + & - & + & - \\
\hline 13 & 43 & $M$ & Germany & Granuloma & Thigh & + & - & + & - \\
\hline 14 & 54 & $M$ & Germany & Spondylitis & Vertebra & + & - & - & - \\
\hline 15 & 63 & $M$ & Germany & BCGitis & Urinary bladder & + & + & + & - \\
\hline 16 & 77 & M & Germany & Chronic inflammation & Chest wall & + & - & + & - \\
\hline 17 & 49 & $M$ & Turkey & Granuloma & Larynx & + & - & + & - \\
\hline 18 & 61 & $M$ & Germany & BCGitis & Prostate & + & - & - & - \\
\hline 19 & 55 & $M$ & Germany & Tumour & Lung & + & - & - & - \\
\hline 20 & 58 & M & Germany & Spondylitis & Vertebra & + & - & + & - \\
\hline 21 & 50 & $M$ & Germany & BCGitis & Prostate & + & + & + & - \\
\hline 22 & 64 & $M$ & Germany & TB & Lung & + & - & - & - \\
\hline 23 & 83 & $M$ & Germany & Spondylitis & Vertebra & - & - & + & - \\
\hline 24 & 61 & $M$ & Germany & BCGitis & Prostate & + & - & - & - \\
\hline 25 & 23 & $\mathrm{~F}$ & Germany & $\mathrm{TB}$ & Lung & + & + & - & - \\
\hline 26 & 45 & $M$ & Turkey & TB & Skin & + & + & - & - \\
\hline 27 & 35 & $\mathrm{~F}$ & Africa & Tumour & Tonsilla & + & + & - & - \\
\hline 28 & 45 & $\mathrm{~F}$ & Germany & Tumour & Lung & + & - & - & - \\
\hline 29 & 67 & $M$ & Germany & Tumour & Prostate & + & - & + & - \\
\hline 30 & 58 & $\mathrm{~F}$ & Germany & TB & Lung & + & + & - & - \\
\hline 31 & 34 & $M$ & Arabia & $\mathrm{TB}$ & Lung & + & - & - & - \\
\hline 32 & 58 & $M$ & Germany & Tumour & Lymph node & + & + & - & - \\
\hline 33 & 61 & $M$ & Germany & $\mathrm{TB}$ & Lung & + & + & + & - \\
\hline 34 & 75 & $\mathrm{~F}$ & Germany & $\mathrm{TB}$ & Lung & + & + & + & - \\
\hline 35 & 54 & $M$ & Germany & Tumour & Prostate & + & - & + & - \\
\hline 36 & 76 & M & Germany & Tumour & Lung & + & - & + & - \\
\hline 37 & 59 & M & Germany & Tumour & Lung & + & + & + & + \\
\hline 38 & 50 & $\mathrm{~F}$ & Germany & Epidural tumour & Spinal & + & + & - & - \\
\hline 39 & 87 & $\mathrm{~F}$ & Croatia & Tumour & Lung & + & + & + & + \\
\hline 40 & 24 & $\mathrm{~F}$ & Germany & Tumour & Pelvis & + & + & + & + \\
\hline 41 & 71 & $\mathrm{~F}$ & Germany & TB & Lung & + & + & + & + \\
\hline 42 & 30 & $M$ & Russia & Tumour & Lymph node & + & + & + & - \\
\hline 43 & 19 & $M$ & Arabia & Spondylitis & Vertebra & + & + & + & - \\
\hline 44 & 55 & $\mathrm{~F}$ & Germany & TB & Lung & + & + & + & + \\
\hline 45 & 30 & $M$ & Pakistan & Spondylitis & Vertebra & + & + & + & - \\
\hline 46 & 31 & $\mathrm{~F}$ & Pakistan & Tumour & Pelvis & + & + & + & - \\
\hline 47 & 87 & $\mathrm{~F}$ & Germany & TB & Lung & - & - & + & + \\
\hline 48 & 77 & $\mathrm{~F}$ & Germany & Spondylitis & Vertebra & + & + & + & + \\
\hline
\end{tabular}


Table 2 Primer sequences and polymerase chain reaction conditions used in our study

\begin{tabular}{|c|c|c|c|c|c|c|}
\hline Locus & Direction & Primers & Product size & Parameters & Cycles & Ref \\
\hline IS6110 & $\begin{array}{l}F \\
R\end{array}$ & $\begin{array}{l}\text { CTCGTCCAGCGCCGCTTCGG } \\
\text { CCTGCGAGCGTAGGCGTCGG }\end{array}$ & $123 \mathrm{bp}$ & $\begin{array}{l}94^{\circ} \mathrm{C}, 68^{\circ} \mathrm{C} \text {, and } 72^{\circ} \mathrm{C} \\
1 \text { min each }\end{array}$ & 45 & 10 \\
\hline katG & $\begin{array}{l}F \\
R\end{array}$ & $\begin{array}{l}\text { TCAGCCACGACCTCGTCGG } \\
\text { AGGCGGATGCGACCACCGT }\end{array}$ & $163 \mathrm{bp}$ & $\begin{array}{l}94^{\circ} \mathrm{C}, 65^{\circ} \mathrm{C} \text {, and } 72^{\circ} \mathrm{C} \\
1 \text { min each }\end{array}$ & 43 & 18 \\
\hline gyrA & $\begin{array}{l}F \\
R\end{array}$ & $\begin{array}{l}\text { CGAGACCATGGGCAACTACCA } \\
\text { CATTGCCTGGCGAGCCGAA }\end{array}$ & $131 \mathrm{bp}$ & $\begin{array}{l}94^{\circ} \mathrm{C}, 65^{\circ} \mathrm{C} \text {, and } 72^{\circ} \mathrm{C} \\
1 \text { min each }\end{array}$ & 43 & 18 \\
\hline TbD1 int & $\begin{array}{l}F \\
R\end{array}$ & $\begin{array}{l}\text { AAGGACGAAAGGATCGTCAA } \\
\text { AAAACAGCAAGATCGGCAAC }\end{array}$ & $135 \mathrm{bp}$ & $\begin{array}{l}94^{\circ} \mathrm{C}, 63^{\circ} \mathrm{C} \text {, and } 72^{\circ} \mathrm{C} \\
1 \text { min each }\end{array}$ & 40 & - \\
\hline TbD1 fla & $\begin{array}{l}F \\
R\end{array}$ & $\begin{array}{l}\text { CGGTTATCGAAAGGCTAACG } \\
\text { TACCGTCGATCGTGTCAAAG }\end{array}$ & $96 \mathrm{bp}$ & $\begin{array}{l}94^{\circ} \mathrm{C}, 62^{\circ} \mathrm{C} \text {, and } 72^{\circ} \mathrm{C} \\
1 \text { min each }\end{array}$ & 40 & - \\
\hline RD9 int & $\begin{array}{l}F \\
R\end{array}$ & $\begin{array}{l}\text { GTGGTCATCGAGGTCCAGAT } \\
\text { GCCTGGGTGCATTACCTACT }\end{array}$ & $204 \mathrm{bp}$ & $\begin{array}{l}94^{\circ} \mathrm{C}, 60^{\circ} \mathrm{C} \text {, and } 72^{\circ} \mathrm{C} \\
1 \text { min each }\end{array}$ & 40 & - \\
\hline RD9 fla & $\begin{array}{l}F \\
R\end{array}$ & $\begin{array}{l}\text { GTGACGGTATCGTCGAGCAG } \\
\text { TACCTGGAGGACCAGCTGAA }\end{array}$ & 178 bp & $\begin{array}{l}94^{\circ} \mathrm{C}, 55^{\circ} \mathrm{C} \text {, and } 72^{\circ} \mathrm{C} \\
1 \text { min each }\end{array}$ & 40 & - \\
\hline $\mathrm{mtp} 40$ & $\begin{array}{l}F \\
R\end{array}$ & $\begin{array}{l}\text { CTGGTCGAATTCGGTGGAGT } \\
\text { ATGGTCTCCGACACGTTCGAC }\end{array}$ & $152 \mathrm{bp}$ & $\begin{array}{l}94^{\circ} \mathrm{C}, 64^{\circ} \mathrm{C} \text {, and } 72^{\circ} \mathrm{C} \\
1 \text { min each }\end{array}$ & 45 & 19 \\
\hline oxyR & $\begin{array}{l}F \\
R\end{array}$ & $\begin{array}{l}\text { CGCGCTGTCAGAGCTGACTT } \\
\text { TCTGCGGAATCAGTGTCACC }\end{array}$ & $150 \mathrm{bp}$ & $\begin{array}{l}94^{\circ} \mathrm{C}, 60^{\circ} \mathrm{C} \text {, and } 72^{\circ} \mathrm{C} \\
1 \text { min each }\end{array}$ & 45 & 19 \\
\hline pncA & $\begin{array}{l}F \\
R\end{array}$ & $\begin{array}{l}\text { ATCAGCGACTACCTGGCCGA } \\
\text { GATTGCGACGTGTCCAGAC }\end{array}$ & $180 \mathrm{bp}$ & $\begin{array}{l}94^{\circ} \mathrm{C}, 66^{\circ} \mathrm{C} \text {, and } 72^{\circ} \mathrm{C} \\
1 \mathrm{~min} \text { each }\end{array}$ & 45 & 19 \\
\hline
\end{tabular}

Biosystems, Weiterstadt, Germany). Automatic sequencing was performed on an ABI PRISM 310 genetic analyser (Applied Biosystems).

\section{Spoligotyping}

All samples with positive amplification of IS6110 were subjected to further analysis by spoligotyping. The method was performed as described previously. ${ }^{11}{ }^{12}$ Briefly, this analysis permits the evaluation of variable sequences located in the direct repeat region of the genome of $M$ tuberculosis complex members by hybridisation of biotin labelled PCR products to a set of immobilised spacer oligos that represent spacers of known sequence. Hybridisation patterns vary between $M$ tuberculosis complex strains because of differences in the presence of the non-repetitive DNA spacers. This allows a clear differentiation between $M$ tuberculosis and $M$ bovis strains, as a result of the absence of spacers 39 to 43 in all known $M$ bovis isolates, and the identification of subspecies or certain genetically related families. ${ }^{12}$

\section{Application of strain specific/typical primer pairs}

In a further step, we tested the specimens for the absence or presence of an $M$ tuberculosis specific deletion (TbDl) and the loss of region of difference 9 (RD9), which is characteristic of $M$ africanum, $M$ microti, and $M$ bovis strains. ${ }^{13}$ In addition, partial gene sequences of oxyR, pncA, mtp40, katG, and gyrA, which have been shown to vary between different strains of tuberculosis bacilli, were analysed to characterise the detected $M$ tuberculosis strains further. ${ }^{13}$ The mtp40 region, located in the phospholipase A gene, is present in about $90 \%$ of $M$ tuberculosis strains and absent in most of the $M$ bovis isolates. ${ }^{14}$ The pseudogene oxyR presents a polymorphism at nucleotide 285 (oxyR285) and the pncA (pyrazinamidase) gene differs between $M$ tuberculosis and $M$ bovis by a mutation at codon 57 (pncA57). ${ }^{15}{ }^{16}$ Mycobacterium tuberculosis strains were further divided into three different genetic types based on sequence polymorphism of katG codon 463 (katG463) and gyrA codon 95 (gyrA95), as defined by Sreevatsan et al. ${ }^{17}$
Group 1 is characterised by katG463 CTG (Leu), gyrA95 ACC (Thr); group2 shows katG463 CGG (Arg), gyrA95 ACC (Thr); and group3 exhibits katG463 CGG (Arg), gyrA95 AGC (Ser).

For all amplifications, the PCR reaction mix contained $10 \mathrm{mM}$ Tris/HCl (pH 8.3), 50mM KCl, 1.5mM MgCl $2,200 \mu \mathrm{M}$ of each deoxynucleotide trisphosphate (Amersham Pharmacia, Uppsala, Sweden), $1 \mu \mathrm{M}$ of each primer, $0.025 \mathrm{U} / \mu \mathrm{l}$ AmpliTaq Gold (PE Biosystems, Foster City, California, USA), and $0.5 \mu \mathrm{l}$ extracted DNA to a final volume of $20 \mu \mathrm{l}$. Primers targeting partial gene sequences of $\mathrm{katG}$ and gyrA, ${ }^{18}$ oxyR, pncA, and mtp $40^{19}$ were used as described in the literature. New primer sets were designed for the amplification of RD9 and TbDl. Table 2 lists the details of the primer sequences and PCR conditions used.

\section{Identification of amplification products}

All PCR products were identified by gel electrophoresis in a $2 \%$ agarose gel and were visualised by ethidium bromide staining plus ultraviolet light. For sequencing, the products were purified and subjected to sequencing as described above.

\section{RESULTS}

\section{Rate of molecular identification of $M$ tuberculosis complex DNA}

Nineteen of the 48 biopsy samples showed a specific positive amplification product in the IS6110 PCR reaction (fig 1). The specificity of all positive amplification reactions was confirmed by typical cleavage in restriction enzyme digestion and in several cases by direct sequencing showing the expected sequence known from database source (BLASTN). ${ }^{20}$ Therefore, in 19 cases the presence of human pathogenic mycobacterial DNA was molecularly confirmed. Furthermore, all eight samples with histochemically positive acid fast bacilli staining were confirmed by the molecular analysis. In addition, a specific molecular diagnosis was seen in 11 cases without histological evidence of tubercle bacilli (table 3 ). 


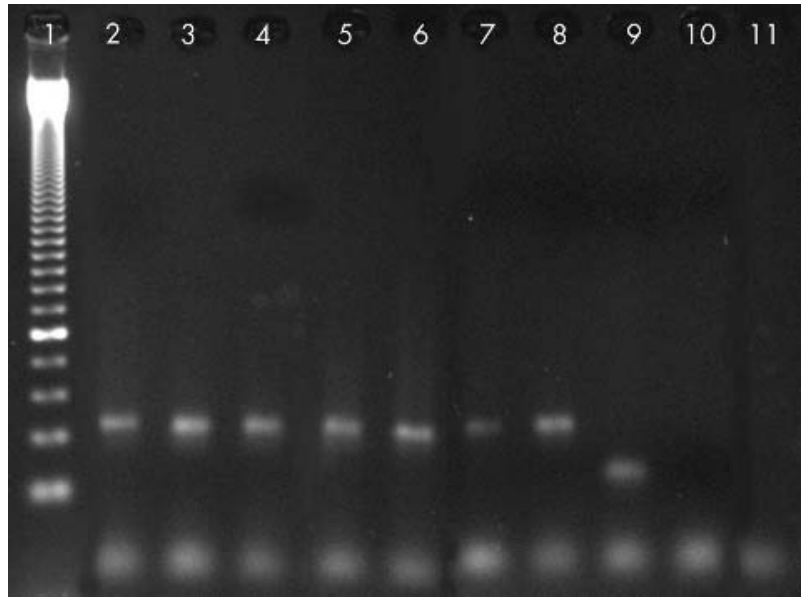

Figure 1 Polymerase chain reaction (PCR) amplification of a $123 \mathrm{bp}$ fragment of IS6110. Lane 1, 50 bp ladder; lanes 2-8, paraffin wax embedded samples, lanes 9-10, extraction controls; lane 11, PCR control.

\section{Further characterisation of mycobacterial DNA by spoligotyping}

The 19 IS6110 positive cases were then subjected to further characterisation by spoligotyping. Typical spoligotyping signatures were obtained for 11 samples, whereas five cases produced an incomplete pattern with only few and "patchy" hybridisation signals (fig 2). No spoligotyping signature could be obtained from the remaining three cases. Of the 11 successfully obtained spoligotyping signatures seven revealed a typical $M$ tuberculosis pattern. This is characterised by the presence of spacers 37 to 43 . Furthermore, in six cases spacers 33 to 36 were absent, which is also characteristic of $M$ tuberculosis. ${ }^{12}$ Two cases (47 and 48 ) showed spoligotyping patterns that are listed in an international database and resemble two of the most common signatures worldwide (shared types numbers 50 and 53). ${ }^{21}$ One further case (7) has previously been described in Houston, Texas, ${ }^{22}$ and resembles a further shared type (280) of the database. The signatures of three further $M$ tuberculosis cases were distinct from all of the as yet classified and identified substrains.

In four samples, spacers were detected at positions 33 to 36 , whereas no hybridisation signal was detected for spacers 39 to 43 , a pattern that is characteristic of $M$ bovis strains. ${ }^{14}$
One case (37) showed a characteristic signature for $M$ bovis subtype caprae, ${ }^{23}$ whereas the remaining three cases could not be attributed to the signatures identified to date.

In eight cases, only incomplete or no spoligotyping signatures were obtained. Therefore, strain identification or differentiation between the members of the $M$ tuberculosis complex could not be performed in these samples.

\section{Mycobacterial strain and substrain identification by specific gene analysis}

PCR amplification of the variable regions TbDl and RD9 and the partial gene sequences oxyR, pncA, mtp40, katG, and gyrA (figs 3 and 4) provided fewer positive cases when compared with the IS6110 amplification data. This is probably the result of differing amounts and states of preservation of mycobacterial DNA between the various samples, and it is not surprising that the multicopy gene IS6110 was more informative than the single copy genes.

The deletion analysis revealed that all seven $M$ tuberculosis cases (as demonstrated by the spoligotyping pattern) lacked TbDl, and in six of these samples RD9 was present. This confirms the presence of $M$ tuberculosis DNA. In addition, in five $M$ tuberculosis cases a katG(463) CTG $\rightarrow$ CGG and/or gyrA(95) ACC $\rightarrow$ AGC mutation was detected. According to Sreevatsan et al, ${ }^{17}$ these samples belong to $M$ tuberculosis genetic groups 2 or 3 and resemble "modern" $M$ tuberculosis strains. In the two remaining cases, no katG or gyrA specific sequences could be retrieved.

In two of the $M$ bovis cases TbDl was present and in one RD9 was deleted. This is again very typical of $M$ bovis. In addition, no mutations were found in the kat $G$ or gyrA sequences, which again confirms the presence of $M$ bovis.

In all seven $M$ tuberculosis samples, the partial gene sequence of oxyR showed the typical nucleotide $\mathrm{G}$ at position 285, whereas in one $M$ bovis case a characteristic mutation was detected at this position ( $\mathrm{G} \rightarrow \mathrm{A}$; fig 5 ). No mutations were found in the pncA gene sequence at position 57 , specific for $M$ tuberculosis and pyrazinamide (PZA) susceptible $M$ bovis isolates. A fragment of the mtp40 gene, typically present in $M$ tuberculosis strains, was amplified in six of the $M$ tuberculosis and one of the not specified cases.

Table 3 summarises the results of the further characterisation of the $M$ tuberculosis complex positive samples.

\section{DISCUSSION}

We successfully applied the spoligotyping technique for the identification of strains of human pathogenic mycobacteria

Table 3 Molecular results of IS6110 positive cases

\begin{tabular}{|c|c|c|c|c|c|c|c|c|c|c|c|c|c|}
\hline Case & $\beta$ actin & IS61 10 & Spoligotyping & oxyR & pncA & mtp40 & katG & gyrA & TbD1 int & TbD1 fla & RD9 int & RD9 fla & Genetic group \\
\hline 1 & + & + & $M$ bovis & - & - & - & - & + & + & - & - & - & $?$ \\
\hline 2 & + & + & Incomplete & G & + & - & - & C & + & - & - & - & 1,2 \\
\hline 6 & + & + & - & - & - & - & - & C & - & - & + & - & 1,2 \\
\hline 7 & + & + & $M$ tuberculosis & G & $\mathrm{C}$ & + & - & G & - & + & + & - & 3 \\
\hline 9 & + & + & - & - & - & - & - & + & + & - & - & - & $?$ \\
\hline 11 & + & + & $M$ tuberculosis & - & $\mathrm{C}$ & + & - & + & - & + & + & - & $?$ \\
\hline 15 & + & + & $M$ bovis & - & - & - & - & + & - & - & - & - & $?$ \\
\hline 20 & + & + & Incomplete & - & - & - & - & - & - & + & + & - & $?$ \\
\hline 21 & + & + & $M$ bovis & - & - & - & - & C & - & - & - & - & 1,2 \\
\hline 25 & + & + & Incomplete & - & - & - & - & - & - & - & - & - & $?$ \\
\hline 33 & + & + & - & - & - & - & - & + & - & - & + & - & $?$ \\
\hline 36 & + & + & Incomplete & - & - & - & - & C & - & - & - & - & 1,2 \\
\hline 37 & + & + & $M$ bovis & $A$ & $\mathrm{C}$ & - & $T$ & C & + & - & - & + & 1 \\
\hline 39 & + & + & M tuberculosis & G & C & - & G & C & - & + & - & - & 2 \\
\hline 40 & + & + & M tuberculosis & G & C & + & - & C & - & + & + & - & 2,3 \\
\hline 41 & + & + & Incomplete & G & C & + & - & C & - & + & + & - & 2,3 \\
\hline 44 & + & + & M tuberculosis & G & - & + & - & - & - & + & + & - & $?$ \\
\hline 47 & + & + & M tuberculosis & G & $\mathrm{C}$ & + & G & + & - & + & + & - & 2,3 \\
\hline 48 & + & + & M tuberculosis & G & - & + & G & C & - & + & + & - & 2 \\
\hline
\end{tabular}




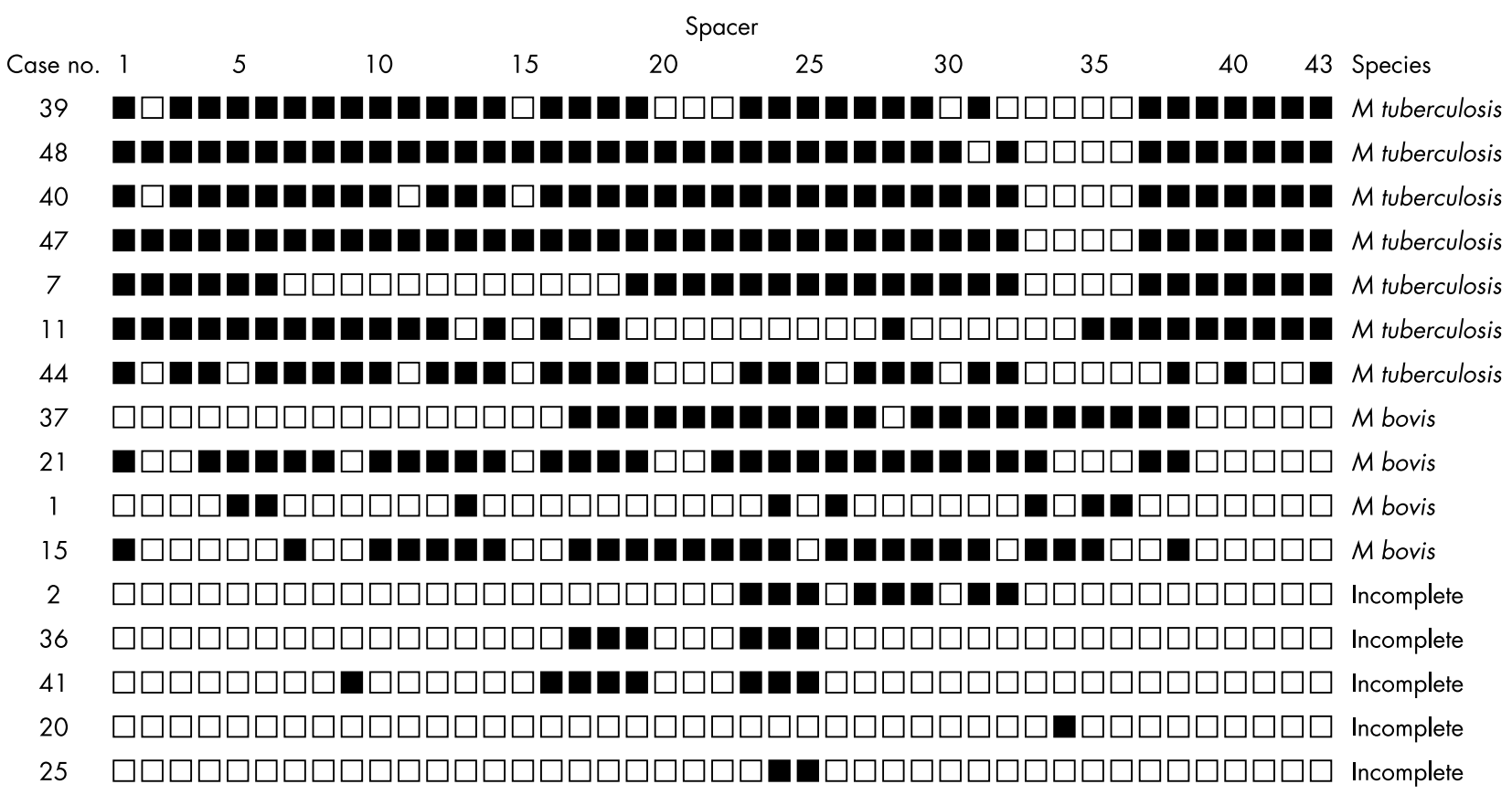

Figure 2 Spoligotyping results of the paraffin wax embedded samples.

in approximately two thirds of our archival tissue samples. In contrast to former studies on paraffin wax embedded samples, ${ }^{78}$ cases with unclear histomorphology were also included and tested for the presence of mycobacterial DNA. Using this emerging technique for the identification and characterisation of the direct repeat locus of the mycobacterial genome, we provide clear evidence that such an analysis can be performed successfully in a high proportion of

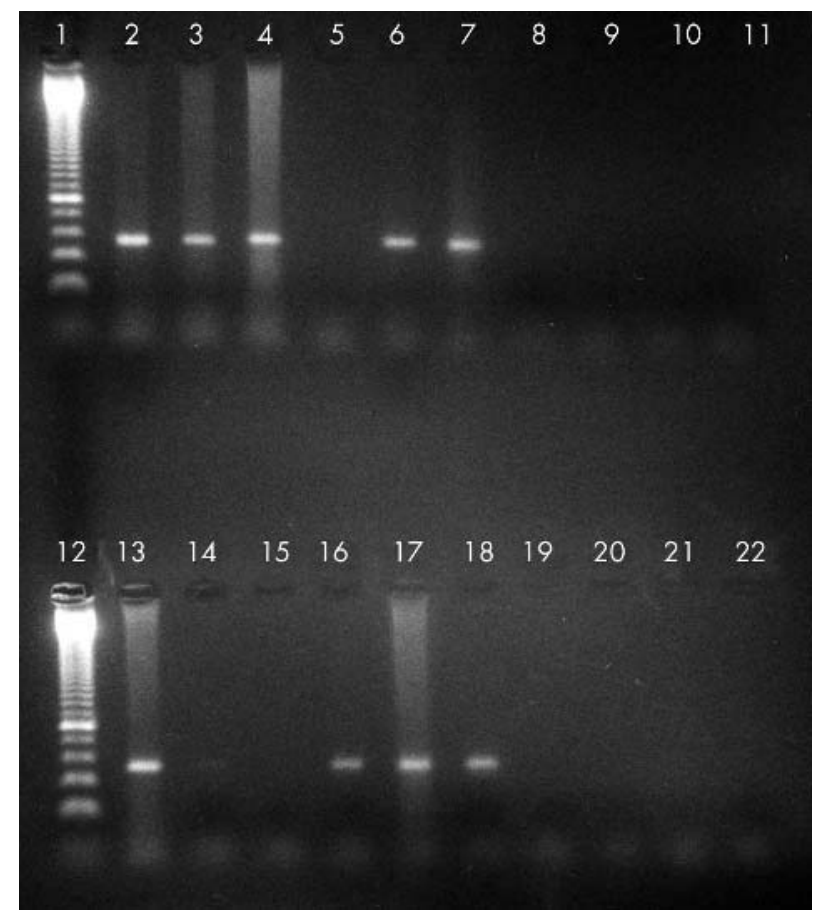

Figure 3 Polymerase chain reaction (PCR) amplification of a $131 \mathrm{bp}$ fragment of the gyrA gene. Lanes 1 and 12, 50 bp ladder, lanes 2-11 and 13-14, paraffin wax embedded samples; lanes 15-21, extraction controls, lane 22, PCR control. samples. Therefore, this approach not only extends and confirms the molecular diagnosis in those cases identified by the frequently used IS6110 sequence of the mycobacterial DNA complex, but it also provides information on distinct strains of human pathogenic mycobacteria. Using this approach, the identification of mycobacterial strains and substrains may show changes in re-emerging mycobacterial infection or may trace double infections by various

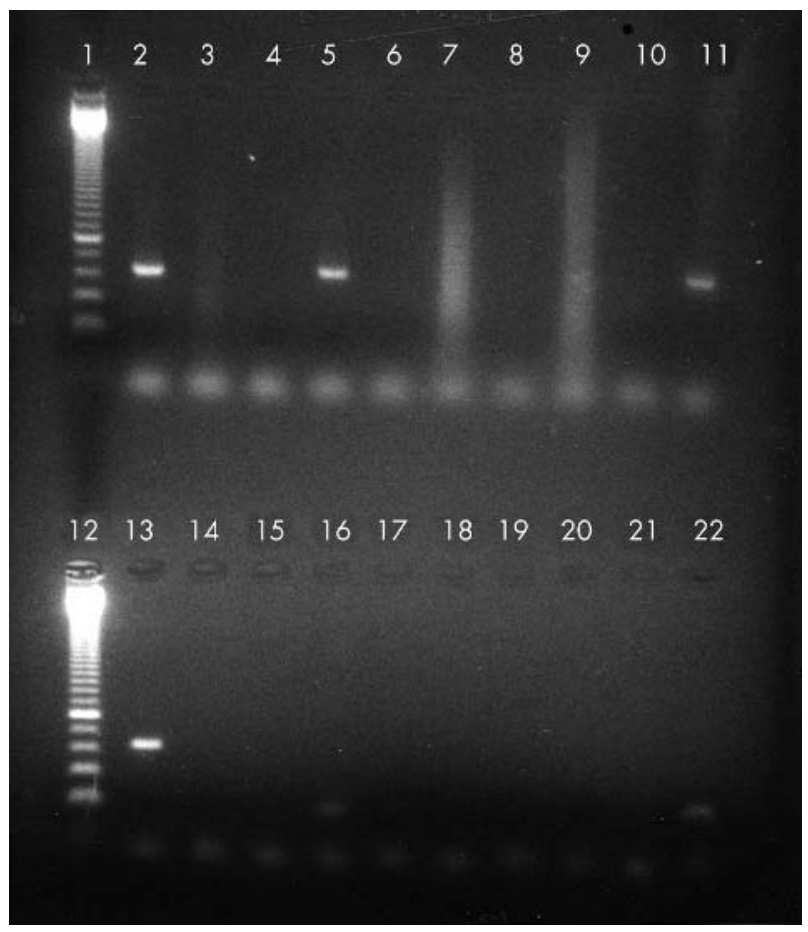

Figure 4 Polymerase chain reaction (PCR) amplification of a $163 \mathrm{bp}$ fragment of the katG gene. Lanes 1 and 12, 50 bp ladder; lanes 2-7 and 13-18, paraffin wax embedded samples; lanes 8-11 and 19-21, extraction controls; lane 22, PCR control. 


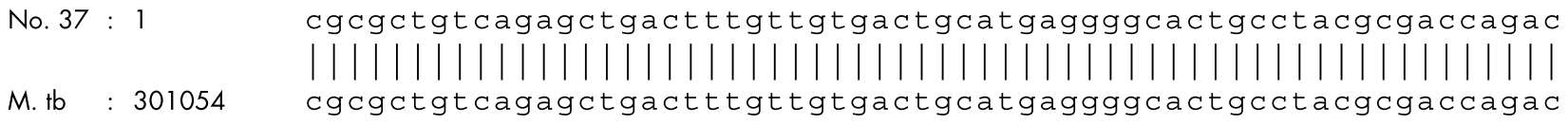

No. $37: 61$

M. tb : 300994

No. $37: 121$

M. tb : 300934 gctcgatgctgcccaacaccogggcggtgtagctggccaccgtcgtgcagtgcgtgaccg |||||||||||||||||||||||||||||||||||||||||||||| $\mid$ gctcgatgctgcccaacaccegggeggtgtggctggccaccgtcgtgcagtgcgtgaccg

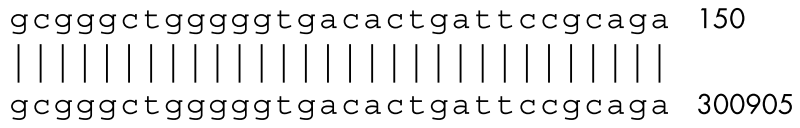

Figure 5 Partial sequence of the oxyR pseudogene. Compared with the Mycobacterium tuberculosis reference strain sequence data, case number 37 showed a mutation ( $G$ to $A$, grey marking) in the oxyR pseudogene characteristic of $M$ bovis.

mycobacterial strains. It may also facilitate the recording of the epidemiology and spread of mycobacteria even in archival material. Furthermore, our analysis provides clear evidence that spoligotyping is the technique of choice in archival material, because it was more informative than single gene analysis. This is not surprising, because fixation and chemical processing of the archival material induces alterations of the DNA, potentially resulting in complete or partial loss of the DNA. However, we also provide circumstantial evidence that both approaches (spoligotyping and single gene analysis) produce almost identical results.

As a first step, we made use of the frequently used segment IS6110, which is specifically seen in human pathogenic bacteria of the $M$ tuberculosis complex. Recent discussions on eventual "crossreactions" with other (non-pathogenic) mycobacteria provided clear evidence that the approach used here excludes such false results. ${ }^{24}{ }^{25}$ Using this approach, we were able not only to confirm the presence of mycobacteria in the eight cases where histochemical Ziehl-Neelsen staining had already demonstrated mycobacterial infection, but also found that 11 of the 41 cases with histologically unclear or suspected mycobacterial infection were molecularly positive. This rate is well within the limits of several other previous studies where formalin fixed, paraffin wax embedded tissue samples from patients with clinically suspected TB had been included. ${ }^{326}$ The amplification of mycobacterial DNA in the acid fast bacilli positive specimens clearly underlines the high specificity of the IS6110 based TB PCR. Therefore, we confirm the results of former studies that had focused on the specificity and sensitivity of this molecular approach. ${ }^{36-29}$

Moreover, the extracted DNA can be used for further differentiation of the species of the $M$ tuberculosis complex by spoligotyping. Comparison of the signatures with an international database revealed conformity with patterns obtained from other studies from different geographical regions. Two spoligotyping signatures have been identified as being common worldwide, and another has been described in Houston, Texas, USA. ${ }^{22}$ Three further patterns are also typical of $M$ tuberculosis, but have not been found on the database. At present, we can only speculate whether or not these three signatures represent "new", hitherto unreported substrains, or whether they were incomplete and should therefore not be further evaluated. However, we have to be aware that the absence of single spacers can also be caused by isolated dropouts, potentially leading to misinterpretation. One $M$ tuberculosis specific signature appears not to be fully complete, but the presence of spacers 33 to 43 leads to the assumption that this resembles an "ancient" $M$ tuberculosis strain. ${ }^{13}$ Interestingly, at least four $M$ bovis specific signatures were also unambiguously detected by spoligotyping. One of these came from a patient with clinical evidence of pulmonary tuberculosis. This case was clearly identified as a typical pattern of $M$ bovis subtype caprae, ${ }^{30}$ which to date has been isolated mainly from sheep and goats. ${ }^{31}$ Recently, Kubica et al showed that $M$ bovis subtype caprae was responsible for one third of all human tuberculosis cases caused by the bovine tubercle bacillus in Germany between 1999 and 2001. ${ }^{32}$ The three remaining patterns all showed the absence of spacers 3 and 9, and in two cases spacer 16 was also absent. These spacers are usually absent in $M$ bovis BCG strains. ${ }^{12}$ In this context it is very interesting that two of these patients were treated with BCG for urothelial carcinoma of the bladder and, therefore, most probably had developed a local BCG infection. Five further cases revealed an incomplete, patchy pattern, where no further strain differentiation was possible. This can be attributed to poor DNA conservation as a result of fixation and the embedding procedure. It can be assumed that this chemical modification of the tissue samples during processing for histology enhances DNA degradation processes and reduces the amount of detectable bacilli. $^{33}{ }^{34}$ Nevertheless, in a recent study we successfully applied the spoligotyping method to mummified human remains from ancient Egypt. ${ }^{35}$ This revealed the presence of different $M$ tuberculosis and $M$ africanum strains 4000 years ago and demonstrates the high sensitivity of this approach.

\section{"Our analysis provides clear evidence that spoligotyping is the technique of choice in archival material, because it was more informative than single gene analysis"}

The analysis of partial gene sequences of oxyR, pncA, mtp40, katG, and gyrA and testing for the presence or absence of variable gene regions are useful for the further characterisation of the identified $M$ tuberculosis complex strains. The mtp40 sequence has been shown to be specific for $M$ tuberculosis and $M$ africanum..$^{14}$ Single point mutations of the pncA gene and the oxyR locus have been used to differentiate between $M$ bovis and $M$ tuberculosis isolates. ${ }^{15}{ }^{16}$ The sequence polymorphism of the katG and gyrA gene allows the division of the $M$ tuberculosis strains into three genetic groups. ${ }^{17}$ In our study, all $M$ tuberculosis strains identified by spoligotyping could be confirmed by either the presence of the mtp40 sequence or by showing the typical oxyR and pncA wild-type sequences. Two further cases with incomplete spoligotyping patterns also contained the $M$ tuberculosis specific oxyR sequence and are therefore most probably $M$ tuberculosis strains. One $M$ bovis case showed the typical mutation of the oxyR locus at nucleotide 285 ( $G$ to A), but had a wild-type pncA gene. In this case, the spoligotyping 


\section{Take home messages}

- Archival paraffin wax embedded material can be used for molecular analysis to identify different Mycobacterium tuberculosis complex strains and can therefore unequivocally be used for the study of the epidemiology and evolution of tuberculosis pathogens

- We successfully applied the spoligotyping technique for the identification of strains of human pathogenic mycobacteria in approximately two thirds of our archival tissue samples

- This technique could potentially provide data on superinfection by various tuberculosis strains and clinically relevant data on multidrug resistant strains

signature showed a pattern specific for the $M$ bovis subtype caprae, which is unusually susceptible to PZA. The PZA resistance, similar to that seen in the $M$ bovis subtype bovis strains, is based on a single point mutation in the pncA gene (see above). Thus, the absence of the pncA mutation in this case confirmed the spoligotyping result.

Based on the results of the katG and gyrA sequence analysis, five of the $M$ tuberculosis samples could be classified as group 2 or 3 according to the scheme proposed by Sreevatsan et al..$^{17}$ As expected, no mutations of the katG or gyrA gene were found in the $M$ bovis strains. These findings are substantiated by the investigation of the $M$ tuberculosis specific deletion TbDl and RD9, which is absent in the $M$ africanum, $M$ microti, and $M$ bovis strains. ${ }^{13}$ In all seven $M$ tuberculosis cases, TbDl was deleted and a further six cases showed the presence of RD9, whereas in one $M$ bovis sample RD9 was deleted. Therefore, all $M$ tuberculosis cases identified in our study could be classified as "modern" $M$ tuberculosis strains.

In summary, our study clearly shows that archival paraffin wax embedded material can be used for epidemiological and evolutionary studies. We present circumstantial evidence that the epidemiology of $M$ tuberculosis complex strains and substrains can be evaluated on archival material that predates major population movements in recent times. Our results suggest that this information might be uncovered with considerable success. Furthermore, this technique could potentially provide data on superinfection by various TB strains and clinically relevant data on multidrug resistant strains.

\section{ACKNOWLEDGEMENTS}

This study was supported by a grant from the Deutsche Forschungsgemeinschaft (DFG NE 575/3-4). The technical assistance of Mrs W Grabner and Mrs S Köhler is gratefully acknowledged. Special thanks go to Dr C Sola and Dr N Rastogi, Institute Pasteur, Guadeloupe for access to spoligotyping database SpolDB3 and helpful discussions of the spoligotyping data. Finally, we would like to thank all clinical colleagues of the Academic Hospital Munich-Bogenhausen for providing us with supplementary data on the patients and clinical assessments.

\section{Authors' affiliations}

A R Zink, A G Nerlich, Institute of Pathology, Academic-Teaching Hospital München-Bogenhausen, D-81925 München, Germany

\section{REFERENCES}

1 Ghossein RA, Ross DG, Salomon RN, et al. A search for mycobacterial DNA in sarcoidosis using the polymerase chain reaction. Am J Clin Pathol 1994; 101:733-7.
2 Ikonomopoulos JA, Gorgoulis VG, Zacharatos PV, et al. Multiplex polymerase chain reaction for the detection of mycobacterial DNA in cases of tuberculosis and sarcoidosis. Mod Pathol 1999;12:854-62.

3 Li JY, Lo ST, Ng CS. Molecular detection of Mycobacterium tuberculosis in tissues showing granulomatous inflammation without demonstrable acid-fast bacilli. Diagn Mol Pathol 2000;9:67-74.

4 Hsiao PF, Tzen CY, Chen $\mathrm{HC}$, et al. Polymerase chain reaction based detection of Mycobacterium tuberculosis in tissues showing granulomatous inflammation without demonstrable acid-fast bacilli. Int J Dermatol 2003;42:281-6.

5 Hofman V, Selva E, Landraud L, et al. Value of PCR amplification from formalin-fixed paraffin-embedded tissues in the diagnosis of Mycobacterium tuberculosis infection. Ann Pathol 2003;23:206-15.

6 World Health Organisation. The WHO/IUATLD global project on antituberculosis drug resistance surveillance. Anti-drug resistance in the world. Report 2. Prevalence and trends, WHO/CDS/TB/2000.278. Communicable Diseases. Geneva, Switzerland: World Health Organisation, 2000.

7 van der Zanden AG, Hoentjen AH, Heilmann FG, et al. Simultaneous detection and strain differentiation of Mycobacterium tuberculosis complex in paraffin wax embedded tissues and in stained microscopic preparations. Mol Pathol 1998;51:209-14.

8 Qian L, Van Embden JD, Van Der Zanden AG, et al. Retrospective analysis of the Beijing family of Mycobacterium tuberculosis in preserved lung tissues. J Clin Microbiol 1999:37:471-4.

9 Zink A, Haas CJ, Reischl U, et al. Molecular analysis of skeletal tuberculosis in an ancient Egyptian population. J Med Microbiol 2001;50:355-66.

10 Eisenach KD, Cave MD, Bates JH, et al. Polymerase chain reaction amplification of a repetitive DNA sequence specific for Mycobacterium tuberculosis. J Infect Dis 1990;161:977-81.

11 Zink AR, Sola C, Reischl U, et al. Characterization of Mycobacterium tuberculosis complex DNAs from Egyptian mummies by spoligotyping. I Clin Microbiol 2003;41:359-67.

12 Kamerbeek J, Schouls L, Kolk A, et al. Simultaneous detection and strain differentiation of Mycobacterium tuberculosis for diagnosis and epidemiology. J Clin Microbiol 1997;35:907-14.

13 Brosch R, Gordon SV, Marmiesse M, et al. A new evolutionary scenario for the Mycobacterium tuberculosis complex. Proc Natl Acad Sci U S A 2002:99:3684-9.

14 Liébana E, Aranaz A, Francis B, et al. Assessment of genetic markers for species differentiation within the Mycobacterium tuberculosis complex. J Clin Microbiol 1996;34:933-6.

15 Scorpio A, Zhang Y. Mutations in pncA, a gene encoding pyrazinamidase/ nictoinamidase, cause resistance to the antituberculous drug pyrazinamide in tubercle bacillus. Nat Med 1996;2:662-7.

16 Sreevatsan S, Escalante P, Pan X, et al. Identification of a polymorphic nucleotide in oxyR specific for Mycobacterium bovis. J Clin Microbiol 1996;34:2007-10

17 Sreevatsan S, Pan X, Stockbauer KE, et al. Restricted structural gene polymorphism in the Mycobacterium tuberculosis complex indicates evolutionarily recent global dissemination. Proc Natl Acad Sci U S A 1997:97:9869-74.

18 Fletcher HA, Donoghue HD, Taylor GM, et al. Molecular analysis of Mycobacterium tuberculosis DNA from a family of 18th century Hungarians. Microbiology 2003; 149:143-51

19 Taylor GM, Goyal M, Legge AJ, et al. Genotypic analysis of Mycobacterium tuberculosis from medieval human remains. Microbiology 1999; 145:899-904.

20 Altschul SF, Madden TL, Schaffer AA, et al. Gapped BLAST and PSI-BLAST: a new generation of protein database search programs. Nucleic Acids Res 1997; 25:3389-402.

21 Filliol I, Driscoll JR, van Soolingen D, et al. Global distribution of Mycobacterium tuberculosis spoligotypes. Emerg Infect Dis 2002;8:1347-9.

22 Soini H, Pan X, Amin A, et al. Characterization of Mycobacterium tuberculosis isolates from patients in Houston, Texas, by spoligotyping. J Clin Microbiol 2000;38:669-76.

23 Niemann S, Richter E, Rusch-Gerdes S. Differentiation among members of the Mycobacterium tuberculosis complex by molecular and biochemical features: evidence for two pyrazinamide-susceptible subtypes of $M$. bovis. J Clin Microbiol 2000;38:152-7

24 Hellyer TJ, DesJardin LE, Assaf MK, et al. Specificity of IS61 10-based amplification assays for Mycobacterium tuberculosis complex. J Clin Microbiol 1997;35:799-801.

25 Marchetti G, Gori A, Catozzi L, et al. Evaluation of PCR in detection of Mycobacterium tuberculosis from formalin-fixed, paraffin-embedded tissues: comparison of four amplification assays. J Clin Microbiol 1998;36:1512-17.

26 Park do Y, Kim JY, Choi KU, et al. Comparison of polymerase chain reaction with histopathologic features for diagnosis of tuberculosis in formalin-fixed, paraffin-embedded histologic specimens. Arch Pathol Lab Med 2003;127:326-30.

27 Salian NV, Rish JA, Eisenach KD, et al. Polymerase chain reaction to detect Mycobacterium tuberculosis in histologic specimens. Am J Respir Crit Care Med 1998; 158:1150-5

28 Vago L, Zerbi P, Caldarelli-Stefano R, et al. Polymerase chain reaction for Mycobacterium tuberculosis complex DNA. Use on negative archival ZiehlNeelsen cytologic samples. Acta Cytol 2000;44:1023-8.

29 Miller J, Jenny A, Rhyan J, et al. Detection of Mycobacterium bovis in formalin-fixed, paraffin-embedded tissues of cattle and elk by PCR amplification of an IS6110 sequence specific for Mycobacterium tuberculosis complex organisms. J Vet Diagn Invest 1997:9:244-9.

30 Niemann S, Richter E, Rusch-Gerdes S. Biochemical and genetic evidence for the transfer of Mycobacterium tuberculosis subsp. caprae Aranaz et al. 1999 to the species Mycobacterium bovis Karlson and Lessel 1970 (approved lists 
1980 ) as Mycobacterium bovis subsp. caprae comb. nov. Int J Syst Evol Microbiol 2002;52:433-6.

31 Gutierrez M, Samper S, Jimenez MS, et al. Identification by spoligotyping of a caprine genotype in Mycobacterium bovis strains causing human tuberculosis. J Clin Microbiol 1997;35:3328-30.

32 Kubica T, Rusch-Gerdes S, Niemann S. Mycobacterium bovis subsp. caprae caused one-third of human $M$. bovis-associated tuberculosis cases reported in Germany between 1999 and 2001. J Clin Microbiol 2003:41:3070-7.
33 Greer CE, Peterson SL, Kiviat NB, et al. PCR amplification from paraffinembedded tissues. Effects of fixative and fixation time. Am J Clin Pathol 1991;95:117-24.

34 Karlsen F, Kalantari $M$, Chitemerere $M$, et al. Modifications of human and viral deoxyribonucleic acid by formaldehyde fixation. Lab Invest 1994:71:604-11.

35 Zink AR, Sola C, Reischl U, et al. Characterization of Mycobacterium tuberculosis complex DNAs from Egyptian mummies by spoligotyping. J Clin Microbiol 2003;41:359-67.

\section{Clinical Evidence-Call for contributors}

Clinical Evidence is a regularly updated evidence based journal available worldwide both as a paper version and on the internet. Clinical Evidence needs to recruit a number of new contributors. Contributors are health care professionals or epidemiologists with experience in evidence based medicine and the ability to write in a concise and structured way.

\section{Currently, we are interested in finding contributors with an interest in} the following clinical areas:

Altitude sickness; Autism; Basal cell carcinoma; Breast feeding; Carbon monoxide poisoning; Cervical cancer; Cystic fibrosis; Ectopic pregnancy; Grief/bereavement; Halitosis; Hodgkins disease; Infectious mononucleosis (glandular fever); Kidney stones; Malignant melanoma (metastatic); Mesothelioma; Myeloma; Ovarian cyst; Pancreatitis (acute); Pancreatitis (chronic); Polymyalgia rheumatica; Post-partum haemorrhage; Pulmonary embolism; Recurrent miscarriage; Repetitive strain injury; Scoliosis; Seasonal affective disorder; Squint; Systemic lupus erythematosus; Testicular cancer; Varicocele; Viral meningitis; Vitiligo However, we are always looking for others, so do not let this list discourage you.

Being a contributor involves:

- Appraising the results of literature searches (performed by our Information Specialists) to identify high quality evidence for inclusion in the journal.

- Writing to a highly structured template (about 2000-3000 words), using evidence from selected studies, within 6-8 weeks of receiving the literature search results.

- Working with Clinical Evidence Editors to ensure that the text meets rigorous epidemiological and style standards.

- Updating the text every eight months to incorporate new evidence.

- Expanding the topic to include new questions once every 12-18 months.

If you would like to become a contributor for Clinical Evidence or require more information about what this involves please send your contact details and a copy of your CV, clearly stating the clinical area you are interested in, to Claire Folkes (cfolkes@bmigroup.com).

\section{Call for peer reviewers}

Clinical Evidence also needs to recruit a number of new peer reviewers specifically with an interest in the clinical areas stated above, and also others related to general practice. Peer reviewers are health care professionals or epidemiologists with experience in evidence based medicine. As a peer reviewer you would be asked for your views on the clinical relevance, validity, and accessibility of specific topics within the journal, and their usefulness to the intended audience (international generalists and health care professionals, possibly with limited statistical knowledge). Topics are usually 2000-3000 words in length and we would ask you to review between 2-5 topics per year. The peer review process takes place throughout the year, and our turnaround time for each review is ideally 10-14 days.

If you are interested in becoming a peer reviewer for Clinical Evidence, please complete the peer review questionnaire at www.clinicalevidence.com or contact Claire Folkes(cfolkes@bmigroup.com). 